\title{
\& \\ Reviu Implementasi Thorcon Molten Salt Reactor di Indonesia
}

Sahala M. Lumbanraja*, Edwaren Liun

Pusat Kajian Sistem Energi Nuklir,BATAN, JI. Kuningan Barat, Jakarta Selatan, Indonesia

\begin{tabular}{l}
\hline INFORMASI ARTIKEL \\
\hline Riwayat Artikel: \\
Diterima: \\
24 Januari 2018 \\
Diterima dalam bentuk revisi: \\
24 April 2018 \\
Disetujui: \\
8 Agustus 2018 \\
\hline
\end{tabular}

Kata kunci:

Thorcon MSR,

thorium,

temperatur tinggi,

garam cair

\begin{abstract}
ABSTRAK
REVIU IMPLEMENTASI THORCON MOLTEN SALT REACTOR DI INDONESIA. Thorcon Molten Salt Reactor (Thorcon MSR) merupakan jenis PLTN generasi ke-4 yang dirancang oleh Martingle Inc. Amerika Serikat. PLTN ini berbahan bakar, dan berpendingin garam cair, beroperasi pada temperatur tinggi dan tekanannya mendekati tekanan atmosfir. PLTN ini berdaya 1000 MWe yang dihasilkan oleh 4 modul dengan daya masing-masing $250 \mathrm{MWe}$. Makalah ini bertujuan untuk menguraikan dan memberi gambaran tentang kelayakan ThorCon MSR kepada pemangku kepentingan ketika akan diimplementasikan di Indonesia. Metodologi yang digunakan adalah mempelajari berbagai pustaka tentang teknologi Thorcon, ketersediaan SDM, partisipasi nasional dan regulasinya, serta dilakukan dengan analisis SWOT (Strength, Weaknesses, Opportunities, Threats). Jenis PLTN ini layak diimplementasikan dalam jangka panjang di Indonesia karena mempunyai aspek keselamatan tinggi, dan mudah dikonstruksi tetapi berbagai kendala masih perlu diselesaikan seperti status teknologi masih desain konsep, SDM belum tersedia, dan belum mendapat sertifikasi dari lembaga yang berwenang.
\end{abstract}

\begin{abstract}
IMPLEMENTATION REVIEW OF THORCON MOLTEN SALT REACTOR IN INDONESIA. Thorcon Molten Salt Reactor (Thorcon MSR) is a 4th generation fuel NPP designed by Martingle Inc. United States of America. This NPP is a molten salt fuel, liquid-cooled refrigerant, operating at high temperatures and low pressure approaching atmospheric pressure. NPP is $1000 \mathrm{MWe}$ generated by 4 modules with $250 \mathrm{MWe}$ each power. This paper aims to describe and give an overview to stakeholders about feasibility of ThorCon MSR when it will be implemented in Indonesia. The methodology used is to study the various libraries of ThorCon technology, the availability of human resources, national participation and regulation, and is done by SWOT analysis (Strength, Weaknesses, Opportunities, Threats). This type of nuclear power plant is feasible to be implemented in the long term in Indonesia because it has a high safety system, and is easy to construct but various obstacles still need to be resolved such as technology status is still conceptual design, human resources are not yet available, and have not been certified by authorized institution.

Keywords: Thorcon MSR, thorium, high temperature, molten salt
\end{abstract}

(c) 2018 Jurnal Pengembangan Energi Nuklir. All rights reserved

\section{PENDAHULUAN}

Kecelakaan PLTN dengan tingkat terparah, seperti PLTN Fukushima di Jepang[1] mengakibatkan penerimaan masyarakat terhadap PLTN semakin menurun, tetapi hal ini tidak dapat meniadakan kontribusi PLTN sebagai energi bersih dari portofolio kebutuhan energi dunia[2]. Dari aspek regulasi di Indonesia, PLTN yang dapat dibangun di wilayah Indonesia adalah PLTN yang telah teruji pengoperasiannya[3]. Untuk meningkatkan penerimaan masyarakat terhadap PLTN, para vendor mengembangkan teknologi PLTN generasi-IV dengan tingkat keselamatan lebih tinggi dan lebih ekonomis

${ }^{*}$ Penulis korespondensi.

E-mail: sahalal@batan.go.id dibandingkan teknologi PLTN sebelumnya. Salah satu jenis PLTN generasi-IV yang dikembangkan adalah jenis Molten Salt Reactor (MSR)[4-7]. MSR berasal dari pengembangan desain teknologi Molten Salt Reactor Experimental (MSRE) yang dikembangkan oleh Oak Ridge National Laboratory (ORNL) pada tahun 1960-an[815]. MSRE mempunyai daya $8 \mathrm{MWt}$ dan hanya beroperasi selama 4 tahun.

Thorcon merupakan salah satu nama dagang dari beberapa jenis MSR yang berbahan bakar dan berpendingin garam cair. Thorcon dirancang dan dikembangkan oleh Martingale Inc., Amerika Serikat dengan daya total 1000 MWe yang berasal dari 4 modul, dimana setiap modul berdaya 250 MWe[16,17]. 
Tujuan studi ini a dalah untuk menguraikan dan memberi gambaran tentang kelayakan implementasi Thorcon MSR di Indonesia baik dari segi kelayakan teknologi, kemampuan SDM dan regulasi.

\section{TEORI}

MSR merupakan reaktor berbahan bakar cair yang mengalir secara berkelanjutan melalui untai primer[15]. Temperatur operasi Thorcon sebesar $704{ }^{\circ} \mathrm{C}$ dan efisiensinya $45 \%[17]$.

\subsection{Teknologi Thorcon MSR}

Dari hasil studi Thorcon, minimal ada 4 modul dalam satu lokasi tapak yang akan menghasilkan daya listrik sebesar 1000 MWe (4 x 250 Mwe). Setiap modul terdiri dari 2 Can, dimana satu dalam keadaan beroperasi dan lainnya dalam keadaan standby. Can merupakan bagian inti dari Thorcon MSR yang berisi 3 komponen utama, yaitu Pot, penukar panas primer (primary heat exchanger, PHX), dan pompa untai primer (primary loop pump, PLP), seperti ditunjukkan Gambar 1. Setiap Can dapat menghasilkan daya sebesar 557 MWt (250 MWe). PLP berfungsi mengalirkan bahan bakar garam cair dari Pot ke PHX secara terus-menerus dengan laju 3000 $\mathrm{kg} /$ detik. Pot merupakan teras reaktor yang berisi campuran sodium, berilium, uranium dan thorium-fluorida. Tabel 1 menunjukkan karakteristik umum dari ThorCon MSR.

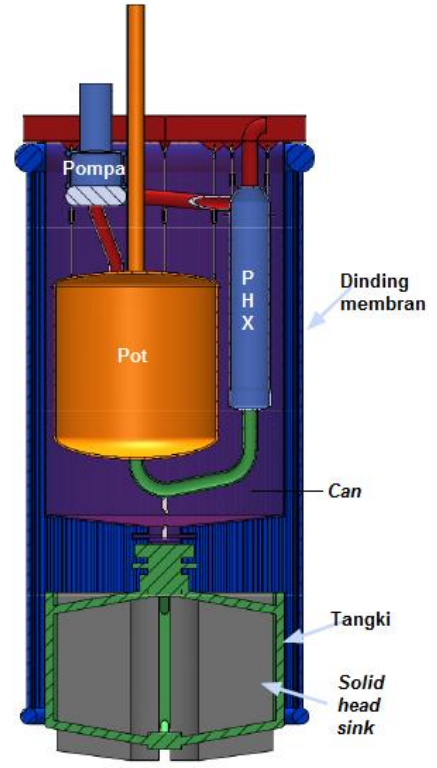

Gambar 1. Tampang Lintang ThorCon Can Silo[16-19].
Tabel 1. Karakteristik Umum ThorTHORCONCon MSR[16,20-21]

\begin{tabular}{|c|c|c|}
\hline \multicolumn{3}{|c|}{ Parameter Teknik } \\
\hline \multicolumn{2}{|l|}{ Nama Dagang } & Thorcon \\
\hline \multicolumn{2}{|l|}{ Pengembang } & $\begin{array}{l}\text { Martingle Inc. } \\
\text { Amerika Serikat }\end{array}$ \\
\hline \multicolumn{2}{|l|}{ Status desain } & konseptual \\
\hline \multirow[t]{2}{*}{ Kapasitas daya } & termal & $557 \mathrm{MWt}$ \\
\hline \multirow{2}{*}{\multicolumn{2}{|c|}{ Faktor kapasitas }} & $250 \mathrm{MWe}$ \\
\hline & & $90 \%$ \\
\hline \multicolumn{2}{|l|}{ Umur Desain } & 80 tahun \\
\hline \multicolumn{2}{|l|}{ Pendingin } & garam $\mathrm{NaF}, \mathrm{BeF}_{2}$ \\
\hline \multicolumn{2}{|l|}{ Moderator } & Grafit \\
\hline \multicolumn{2}{|l|}{ Sirkulasi primer } & Sirkulasi paksa \\
\hline \multicolumn{2}{|l|}{ Tekanan } & $0,3 \mathrm{MPa}$ \\
\hline \multirow[t]{2}{*}{ Temperatur } & Inlet & $565^{\circ} \mathrm{C}$ \\
\hline & outlet & $704{ }^{\circ} \mathrm{C}$ \\
\hline \multicolumn{2}{|l|}{ Neutron spektrum } & termal \\
\hline \multirow[t]{3}{*}{ Bejana tekan reaktor } & tinggi & $11,74 \mathrm{~m}$ \\
\hline & diameter & $7,26 \mathrm{~m}$ \\
\hline & berat & 400 ton/modul \\
\hline \multirow[t]{4}{*}{ Pot } & tinggi & $5,72 \mathrm{~m}$ \\
\hline & diameter & $4,96 \mathrm{~m}$ \\
\hline & berat & $\begin{array}{l}382 \text { ton (tanpa } \\
\text { bb)+ }\end{array}$ \\
\hline & & 40,5 ton $\mathrm{bb}$ \\
\hline \multicolumn{2}{|c|}{ Konfigurasi pendingin reaktor } & $\begin{array}{l}\text { Garam bb, garam } \\
\text { sekunder, garam } \\
\text { solar, uap }\end{array}$ \\
\hline \multicolumn{2}{|l|}{ Proses konversi } & Rankine \\
\hline \multirow{2}{*}{\multicolumn{2}{|c|}{ Sistem keselamatan }} & Pasif dan \\
\hline & & Aktif ....... \\
\hline \multicolumn{2}{|l|}{ Garam bb } & $\begin{array}{l}12 \% \text { logam berat } \\
\text { dlm garam } \mathrm{NaBe}\end{array}$ \\
\hline \multirow{2}{*}{\multicolumn{2}{|c|}{ Komposisi logam }} & $80 \%$ Th, \\
\hline & & $\begin{array}{l}16 \% \mathrm{U}-238, \\
4 \% \mathrm{U}-235\end{array}$ \\
\hline \multirow[t]{2}{*}{ Bahan bakar cair } & pengkayaan & $19,7 \%$ \\
\hline & burn-up & $256 \mathrm{GWd} /$ tonU \\
\hline
\end{tabular}

\subsection{Bahan Bakar ThorCon MSR}

Bahan bakar garam cair merupakan campuran sodium, berilium, uranium dan thorium-fluorida, yang disebut nabe[19]. Penggunaan siklus bahan bakar ${ }^{232} \mathrm{Th}^{-233} \mathrm{U}$ pada MSR lebih prospektif dibandingkan dengan siklus bahan bakar ${ }^{238} \mathrm{U}-{ }^{239} \mathrm{Pu}$ karena produksi limbah nuklir berumur panjang lebih minim[22]. Th-232 merupakan bahan fertil yang dapat digunakan sebagai bahan bakar nuklir jika menyerap neutron dan akan berubah menjadi U-233. Bahan bakar thorium menghasilkan sinar gamma sehingga agak mempersulit implementasinya sebagai bahan bakar. Bentuk bahan bakar cair merupakan cara untuk mencegah keberadaan sinar gamma[23]. Neutron berasal dari U-235 dengan pengayaan $19,7 \%[9,20-21]$ yang dicampur dengan bahan bakar garam cair. 
Reaksi nuklir yang terjadi di dalam Pot akan melepaskan panas dengan temperatur $704{ }^{\circ} \mathrm{C}$. Dari perspektif nuklir, garam harus mempuyai sifat tangkapan neutron besar ( tidak parasit) dan daya moderasi tinggi. Pilihan Thorcon menggunakan Be sebagai campuran garam cair karena titik lelehnya rendah, kemampuan moderasinya tinggi, dan akan memancarkan kembali 2 neutron ketika menyerap 1 neutron. Titik leleh rendah akan lebih menguntungkan karena resiko pembekuan lebih kecil, dan memudahkan start-up reaktor.

Satu modul terdiri dari 2 Can (Can A dan B) seperti ditunjukkan Gambar 2a, dimana Can B berisi bahan bakar baru (fresh) dan Can A tanpa bahan bakar. Can yang berisi bahan bakar beroperasi hingga 4 tahun. Ketika umur operasi Can B telah habis, maka bahan bakar tersebut dipindahkan ke dalam tangki untuk dimurnikan lalu dialirkan ke Can A dan siap dioperasikan hingga 4 tahun kemudian. Can lama (B) kemudian berada di silo untuk kurang lebih 4 tahun, hingga panas peluruhan turun

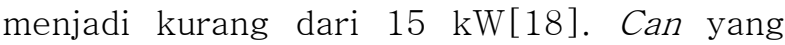
telah selesai didinginkan di dalam silo, kemudian diangkut ke Can Recycling Center (CRC) untuk dibersihkan, diinspeksi, grafit diganti, offgas disimpan dan limbah juga disimpan. Satu siklus bahan bakar berumur hingga 8 tahun. Bahan bakar bekas didinginkan di dalam silo selama 8 hingga 12 tahun. Modul-modul ditempatkan di dalam Silo yang berada di bawah permukaan tanah pada kedalaman tertentu, seperti ditunjukkan pada Gambar 2b.

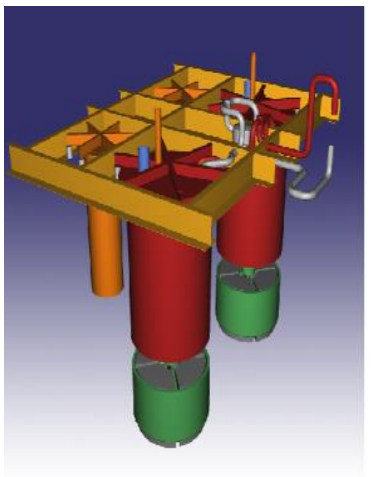

a

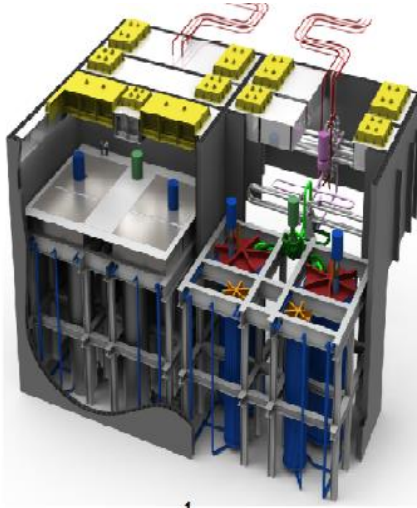

b
Gambar 2. Tampang Lintang (a) Satu Modul[18] dan (b) Dua modul dalam Silo[18,20,21]

\subsection{Konsep Teknologi Keselamatan}

Konsep teknologi keselamatan Thorcon terdiri dari:

- sistem keselamatan pasif[18,20-21]

- dinding membran[16-17]

- tiga lapis gas pembatas antara bahan bakar dan atmosfir[20-21]

Sistem keselamatan pasif dari Thorcon dicirikan dengan temperatur negatif[20-21], tekanan operasi hampir sama dengan tekanan atmosfir[16], dan pelelehan plug valve secara otomatis. Perbedaan antara temperatur operasi $704^{\circ} \mathrm{C}$ dengan titik didih garam cair $1430{ }^{\circ} \mathrm{C}$ yang sangat besar akan memperkecil kemungkinan pelelehan Pot.

Jika temperatur di dalam Pot melebihi temperatur operasi, maka thermokopel akan berfungsi dan secara otomatis menghentikan operasi pompa primer. Hal ini menyebabkan terperatur fluida primer meningkat, flug valve meleleh, dan fluida akan mengalir ke dalam tangki sehingga sistem pengeringan garam bahan bakar cair (fuelsalt rain system) beroperasi secara alamiah[16-17].

Tekanan operasi hampir sama dengan tekanan atmosfir sehingga akan meminimalisir kemungkinan produk fisi ( $\mathrm{Sr}$ dan $\mathrm{Cs}$ ) lepas ke lingkungan jika terjadi kerusakan pada Can. Ketika pasokan daya eksternal ke fasilitas hilang saat terjadi kegagalan operasi, garam bahan bakar akan mengalir secara alamiah hingga kering ke dalam wadah penyimpanan (dilapisi dengan grafit), sehingga secara drastis memperlambat laju fisi dalam garam cair. Selain itu, titik leleh garam fluorida tinggi, maka tidak diperlukan tekanan yang sangat besar untuk menyimpan cairan pendingin, seperti air di reaktor nuklir tradisional[24].

Dinding membran berfungsi untuk mempertahankan temperatur Can di bawah $300{ }^{\circ} \mathrm{C}$ selama operasi normal. Membran berisi cairan yang mengalir dari atas ke dasar Can, seperti ditunjukkan Gambar 1[16-17].

\subsection{Sistem Sekunder}

Fluida pendingin dari sistem sekunder menggunakan garam cair. Campuran garam cair yang umum digunakan adalah dari unsurunsur FLiBe, salah satu contohnya adalah 
campuran $\mathrm{LiF}$ dan $\mathrm{BeF}_{2}[25-26]$. Fluorida dan Li dengan pengayaan tinggi mempunyai tampang lintang neutron kecil dan Be merupakan moderator yang terbaik[27].

Berdasarkan kriteria keselamatan dan kepraktisan, pilihan terhadap campuran garam bahan bakar reaktor ini relatif terbatas[26]. Pilihan didasarkan pada karakteristiknya, yaitu tangkapan neutron, efisiensi moderasi, dan ketersediaan. Ketersediaan Li di dunia sangat terbatas, sehingga Thorcon memilih $\mathrm{F}$ sebagai campuran garam karena $\mathrm{F}$ mempunyai tangkapan netron rendah, berfungsi sebagai moderator yang mempertahankan reaksi berantai lebih besar, dan banyak tersedia. Fluida pendingin yang digunakan di reaktor Thorcon adalah campuran $\mathrm{NaF}$ dan $\mathrm{BeF}_{2}$.

\subsection{Sistem Tersier}

Ketersediaan turbin generator yang menggunakan fluida garam hingga saat ini belum ada, sehingga Thorcon menggunakan sistem tersier, dimana fluida yang digunakan disesuaikan dengan jenis turbin generator yang digunakan. Gambar 3 menunjukkan sistem aliran fluida desain konsep MSR.

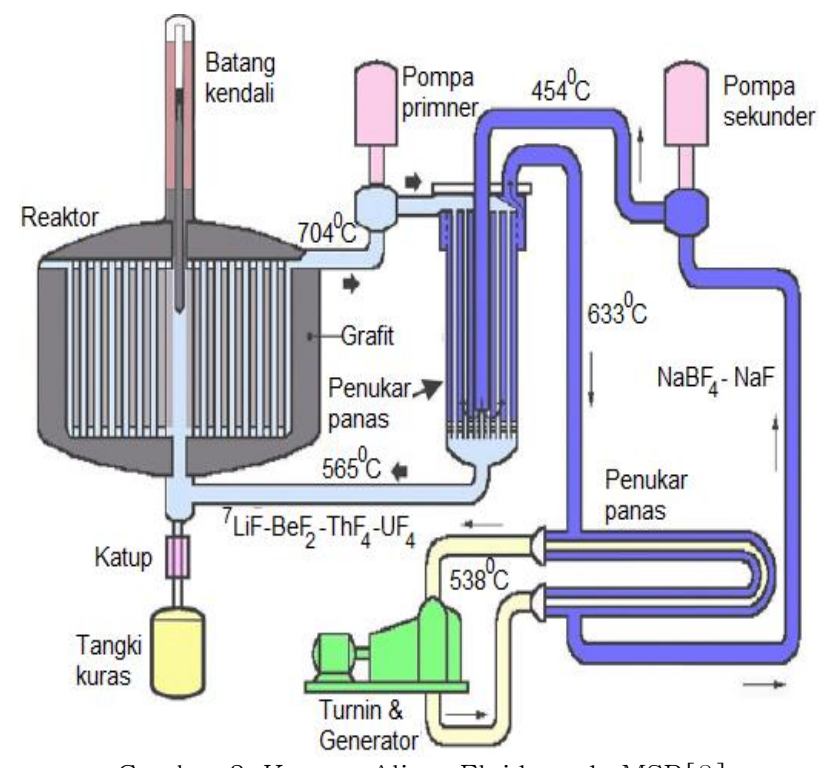

Gambar 3. Konsep Aliran Fluida pada MSR[8].

\section{METODOLOGI}

Metode yang dilakukan dalam studi ini adalah kajian, yaitu mempelajari berbagai pustaka tentang perkembangan teknologi MSR, kemudian dianalisis dengan metode SWOT.

\section{HASIL DAN PEMBAHASAN}

Keuntungan dan kekurangan MSR dibandingan dengan LWR ditunjukkn pada Tabel 2.

Tabel 2. Keuntungan dan Kekurangan MSR Dibandingkan LWR $[17,26]$

\begin{tabular}{lc}
\multicolumn{1}{c}{ Keuntungan } & \multicolumn{1}{c}{ Kekurangan } \\
\hline $\begin{array}{l}\text { - tekanan operasi lebih } \\
\text { rendah }\end{array}$ & $\begin{array}{c}\text { relatif sulit dikembangkan } \\
\text { dengan skala besar }\end{array}$ \\
- tidak membutuhkan & - membutuhkan perubahan \\
batang kendali & regulasi \\
- beroperasi pada & \\
temperatur lebih & \\
tinggi & \\
- efisiensinya lebih & \\
tinggi & \\
- hanya membutuhkan \\
tapak seluas 10 ha \\
- silo ditempatkan \\
hanya dikedalaman 14 \\
m di bawah \\
permukaan tanah \\
untuk daya 1000 MWe
\end{tabular}

Status terkini dari Thorcon MSR adalah dalam tahap desain konseptual. Teknologi MSR dapat memenuhi tujuan reaktor Generasi-IV dalam hal keberlanjutan sumber (pembiak Th), non proliferasi, penghematan sumber daya (siklus bahan bakar Th / U tertutup, tidak ada pengayaan uranium), keamanan (tidak ada cadangan reaktif, koefisien umpan balik sangat negatif), dan pengelolaan limbah [4].

Kendala umum pengdayagunaan MSR yang belum terselesaikan hingga saat ini adalah korosi[28-29]. karena garam cair sangat korosif pada temperatur tinggi[10,30]. Menurut M. Kondo et.al., dan J.W. Koger, laju korosi sangat dipengaruhi oleh kemurnian garam cair dimana pengotor (oksigen dan air terlarut di dalamnya[4, 30-31], temperatur, pelepasan neutron[32], juga disebabkan penggunaan wadah grafit[33-34]. Laju korosi komponen yang bersentuhan langsung dengan garam cair cukup tinggi sehingga mengakibatkan komponen-komponen ini lebih sering diganti sebelum mencapai batas kemampuan material tersebut[32]. Dari hasil penelitian V. Ignatiev, ada tiga (3) hal yang harus dipenuhi MSR agar layak beroperasi, yaitu[31]:

- tingkat kemurnian bahan bakar dan pendingin garam cair harus tinggi, 
- potensial redoks harus dikendalikan secara efektif, dan

- pengujian material harus sesuai kriteria desain acuan.

Menurut Nuclear Regulation Commision (NRC) dan Departement of Energy (DoE) Amerika Serikat, MSR masih memerlukan sumber daya tambahan (SDM, dana, waktu, dan kriteria desain) untuk menyelesaikan dan memastikan keselamatan operasinya berjalan dengan aman dan selamat [32].

Produk fisi (xenon, kripton, lantanida), produk plutonium dan aktinida minor dari hasil pembakaran bahan bakar MSR harus diolah secara langsung (on-line), agar reaktor tetap beroperasi[22].

MSR berbahan bakar thorium akan menghasilkan tritium ketika bereaksi dengan neutron, dimana tritium sangat berbahaya jika masuk ke dalam tubuh karena waktu paruh biologis dan efektif sangat panjang. Penggunaan garam cair sebagai pendingin juga memerlukan desain multi-untai karena turbin garam belum tersedia saat ini. MSR belum pernah disertifikasi oleh NRC[16].

Biaya pembangkitan MSR berbahan bakar thorium lebih rendah dibandingkan dengan PLTN konvensional, karena MSR beroperasi hampir mendekati tekanan atmosfir sehingga material struktur jauh lebih sederhana[35], efisiensi energi lebih tinggi, biaya bahan bakar lebih rendah, dan penanganan bahan bakar yang lebih sederhana [24].

Reaktor berpendingin garam juga memungkinkan untuk dioperasikan pada temperatur lebih tinggi, sehingga akan menghasilkan efisiensi yang lebih besar. Thorium merupakan isotop fertil dan 4 kali lebih melimpah dibandingkan dengan uranium dan biaya mengayaan lebih murah $[16,35]$.

Resistansi proliferasi U-233 lebih baik dibandingkan $\mathrm{Pu}-239$ karena proses daur ulang/pemisahan U-233 lebih rumit dan tidak efektif digunakan sebagai komponen senjata nuklir[28].

Faktor korosi menjadi penyebab operasi MSRE dihentikan. Korosi logam yang disebabkan garam cair temperatur tinggi (sering disebut Hot Corrosion). Penelitian korosi ini dilakukan khususnya terhadap fluorida dan pengembangan alloy yang tahan terhadap korosi. MSRE awalnya menggunakan Hastelloy C, kemudian menggunakan Hastelloy $\mathrm{N}$ (nikel-alloy) temperatur tinggi yang tahan terhadap penuaan dan kegetasan. Namun akibat paparan netron yang cukup lama, kerusakan parah ditemukan pada struktur internalnya.

Reaktor Thorcon dirancang berdaya 1000 MWe yang dihasilkan dari 4 modul dimana setiap modul dapat menghasilkan daya 250 MWe. Modul merupakan sistem primer dari reaktor ini, dimana setiap modul berisi 2 Can. Can merupakan bejana pengungkung yang berisi semua sistem primer yang terdiri pot, pompa primer, PHX, dan tangki. Bahan bakar cair digerakkan oleh pompa agar dapat mengalir dari dalam pot menuju sistem penukar panas (PHX) dan kembali ke dalam pot, dst. Garam cair hanya bisa dialirkan jika pompa berfungsi dengan baik. Reaktor nuklir berbahan bakar garam cair akan menghasilkan unsur tritium $\left(\mathrm{T}_{1 / 2}=12,3\right.$ tahun $)$ sebanyak 60 kali lipat lebih besar daripada reaktor air ringan, oleh karena itu peralatan penyaring untuk membersihkan ditempatkan diantara PHX dan secondary heat exchanger (SDX) [17].

Temperatur operasi garam cair di sistem primer mencapai $704{ }^{\circ} \mathrm{C}$ dan mengandung radioaktivitas tinggi. Garam cair bertemperatur tinggi akan menghasilkan efisiensi tinggi tetapi juga berdampak negatip terhadap sistem instrumentasi dan komponenkomponen sistem primer. Sistem instrumentasi akan lebih mudah rusak dan komponenkomponen lebih mudah korosi.

Reaktor ini menggunakan grafit sebagai moderator. Grafit mudah rusak jika terkena paparan radiasi sehingga umur penggunaannya sangat tergantung kerapatan daya reaktor. Semakin tinggi kerapatan daya, maka umur pemakaian grafit semakin pendek. Thorcon dirancang menggunakan kerapatan daya tinggi sehingga menyebabkan umur pemakaian moderator hanya 4 tahun hingga 5 tahun. Oleh karena itu, umur sistem primer dioperasikan hanya 4 tahun sesuai dengan umur kelayakan moderator grafit.

Pada satu siklus operasi modul, hanya satu Can yang beroperasi, sedangkan Can yang lain dalam keadaan mode cooldown atau stand-by. Satu Can yang berisi bahan bakar hanya dapat digunakan selama 4 tahun 
operasi. Bahan bakar dari siklus pertama dialirkan ke dalam tangki, didinginkan dan dimurnikan kembali. Bahan bakar ini dialirkan kembali ke dalam Can yang baru dan siap digunakan pada siklus yang kedua.

Ketika satu Can yang sedang beroperasi mengalami kendala/kerusakan dan perlu diperbaiki, maka bahan bakar dialirkan ke Can yang baru.

Pergantian bahan bakar berimplikasi pada pergantian seluruh sistem primer ( pot, pompa primer, PHX dan pipa primer dan sebagian pipa sekunder yang ada di dalam PHX karena sudah terpapar radioaktivitas tinggi.

Modul dari reaktor Thorcon merupakan faktor krusial yang perlu dikaji lebih mendalam jika jenis reaktor ini akan diaplikasikan di Indonesia karena maksimal digunakan 8 tahun.

Ketersediaan pemasok bahan bakar Thorcon MSR merupakan kendala yang perlu diantisipasi dengan baik. Satu siklus operasi dari modul dalam keadaan normal hanya berlangsung 8 tahun. Dengan demikian, dalam satu siklus operasi reaktor Thorcon berdaya 1000 MWe harus mengganti 4 modul baru sekaligus jika beroperasi secara normal. Tetapi jika ada kerusakan komponen di dalam satu modul atau lebih dari 4 modul, akan berdampak pada siklus pergantiannya. Hal ini akan berdampak pada kapasitas produksi listriknya dan/atau biaya pembangkitannya. Pengembalian bahan bakar bekas yang berlangsung setiap 8 tahun menjadi kendala karena ada kemungkinan dirompak dan disalahgunakan oleh kelompok yang tidak bertanggung jawab.

Negara yang sedang mengembangkan teknologi MSR masih sangat terbatas, bahkan hingga saat ini belum ada negara yang mengoperasikan reaktor ini secara komersial. Analisis pengimplementasian reaktor ini di Indonesia dilakukan dengan analisis SWOT dan hasilnya ditunjukkan pada Tabel 2.

Tapak PLTN konvensional yang telah selesai dioperasikan harus didekomisioning, khususnya di lokasi nuclear island, sehingga bagian ini tidak dapat dimanfaatkan ulang, sedangkan tapak Thorcon masih dapat dimanfaatkan ulang karena sistem primer (modul) setelah siklus operasinya selesai diangkut ke lokasi khusus yaitu Can Recycling Center (CRC). Dengan demikian, volume seluruh komponen Thorcon yang membutuhkan dekomisioning lebih sedikit dibandingkan dengan PLTN konvensional.

Tabel 2. Analisis SWOT Thorcon di Indonesia

\begin{tabular}{ll}
\multicolumn{1}{c}{ Kekuatan } & \multicolumn{1}{c}{$\begin{array}{c}\text { Kelemahan } \\
\text { (Weaknesses) }\end{array}$} \\
\hline - sistem keselamatan lebih & - SDM terbatas \\
tinggi (tekanan operasi $~$ & - partisipasi nasional kecil \\
tekanan atmosfir) & - teknologi belum teruji \\
- penyiapan tapak lebih & - negara pemasok terbatas \\
mudah & - pendingin sangat korosif \\
- kebutuhan bahan & - dukungan pemerintah dan \\
bangunan lebih sedikit & masyarakat lemah dan tak \\
- pengaruh negatip & stabil \\
terhadap lingkungan lebih & - belum bersertifikasi \\
kecil & - masih dalam desain \\
- waktu konstruksi lebih & konsep \\
singkat & Ancaman \\
\hline Kesempatan (Opportunities) & (Threats) \\
\hline - pemanfaatan pemanfaa & - kompetisi harga listrik \\
Th Indonesia lebih besar & dengan pembangkit fosil \\
- keamanan energi lebih & - penolakan LSM \\
terjamin & - perompakan terhadap \\
- penurunan emisi & bahan bakar bekas \\
- dekomisioning lebih & \\
mudah & \\
\hline
\end{tabular}

Thorcon membutuhkan fluida garam baik untuk keperluan pada sistem primer maupun sistem sekunder. Bentuk dasar garam adalah padat sehingga dibutuhkan energi listrik yang besar untuk mencairkan garam tersebut.

Teknologi MSR pertama kali dikembangkan pada tahun 1950-an untuk keperluan bahan propulsi pesawat terbang. Setelah era MSRE, tidak ada reaktor sejenis yang dibangun, sehingga ketersedian SDM yang menguasai teknologi ini sangat terbatas dan umumnya sudah pensiun, sehingga implementasinya untuk digunakan sebagai pembangkit listrik akan lebih sulit. Desain teknologi Thorcon belum mempunyai lisensi dari otoritas yang berwewenang untuk memberikannya. Keterbatasan SDM Indonesia yang mumpuni untuk mengevaluasi teknologi ini menjadi kendala utama dari implementasinya di Indonesia.

Dari segi regulasi, Thorcon akan mengalami kendala karena reaktor ini masih tahap konseptual desain dan regulasi di Indonesia menyatakan bahwa reaktor komersial yang dapat diimplementasikan harus yang sudah teruji.

Persentase partisipasi nasional untuk Thorcon jauh lebih kecil dibandingkan PLTN konvensional karena hampir semua komponen 
yang akan digunakan dalam bentuk modulmodul sedangkan volume dan kualitas konstruksi sipil Thorcon jauh lebih kecil.

Diversifikasi berbagai sumber energi akan mengurangi ketergantungan dari satu sumber energi. Oleh karena itu, implementasi PLTN di Indonesia dapat menjamin keamanan energi juga akan mengurangi dampak emisi gas rumah kaca.

Secara umum, ketika terjadi kecelakaan nuklir di reaktor Thorcon, radionuklida tidak akan cepat lepas ke lingkungan karena tekanan operasionalnya hampir sama dengan tekanan atmosfir. Tetapi penanganan radionuklida tritium perlu mendapat perhatian ekstra karena garam cair akan menghasilkan tritium 60 kali lebih besar daripada reaktor air ringan.

\section{KESIMPULAN}

Jenis PLTN ini layak untuk dipertimbangkan diimplementasikan di Indonesia karena aspek keselamatan tinggi, penyiapan tapak lebih mudah, volume bahan konstruksi lebih sedikit, waktu konstruksi lebih pendek. Bahan galian Th yang melimpah di Indonesia dapat dimanfaatkan maksimal sehingga mengurangi ketergantungan bahan bakar. Imlementasi PLTN ini juga dapat menurunkan kadar emisi gas rumah kaca. Keterbatasan SDM, dan garam cair yang digunakan untuk bahan bakar dan pendingin yang sangat korosif pada temperatur tinggi merupakan kendala yang perlu dicarikan solusinya.

\section{SARAN/REKOMENDASI}

PKSEN perlu mempertimbangkan dan mengusulkan untuk memasukkan kajian Thorcon sebagai alternatif ke dalam rencana strategis BATAN.

\section{UCAPAN TERIMA KASIH}

Penulis mengucapkan terimakasih kepada Dr. Suparman sebagai kepala bidang Kajian Infrastruktur PKSEN, KPTF yang memberi saran perbaikan makalah ini dan
PKSEN yang memberi anggaran untuk terbitnya jurnal ini.

\section{DAFTAR ACUAN}

[1]. Rr. Arum Puni Rijanti, Sahala M. Lumbanraja, Manajemen risiko kecelakaan nuklir akibat bencana alam, Prosiding Seminar Nasional Teknologi Energi Nuklir 2014

[2]. Sahala M. Lumbanraja, Dharu Dewi, Kajian PLTN SMART lepas pantai jenis struktur berbasis gravitasi untuk Indonesia, Jurnal Pengembangan Energi Nuklir, Vol. Juni 2017

[3]. BAPETEN, Peraturan Pemerintah Nomor 54 Tahun 2012 Tentang Keselamatan dan Keamanan Instalasi Nuklir, Jakarta 2012

[4]. Jérôme Serp et.al., The molten salt reactor (MSR) in generation IV: Overview and perspectives, The molten salt reactor (MSR) in generation IV: Overview and perspectives

[5]. Masahiko Numakura et al., Structural investigation of thorium in molten lithiumecalcium fluoride mixtures for salt treatment process in molten salt reactor, Progress in Nuclear Energy 53 (2011) 994998

[6]. L. Mathieu et al., The thorium molten salt reactor: Moving on from the MSBR, Progress in Nuclear Energy 48 (2006) 664e679

[7]. Sandra Dulla et al., Random effects on reactivity in molten salt reactors, Annals of Nuclear Energy 64 (2014) 353-364

[8]. IAEA, Molten Salt Reactor FUJI, July 28, 2016, https://aris.iaea.org/PDF/MSRFUJI.pdf

[9]. Andrew C. Kadak, A comparison of advanced nuclear technologies Columbia University in the City of New York, March 2017 ,

http://energypolicy.columbia.edu/sites/defa ult/files/energy/A\%20Comparison\%20of\%20 Nuclear\%20Technologies\%20033017.pdf

[10]. A. Nuttin et.al., Potential of thorium molten salt reactors : detailed calculations and concept evolution with a view to large scale energy production, Progress in Nuclear Energy, Vol. 46, No. 1, pp. 77-99, 2005

[11]. David LeBlanc, Molten salt reactors: A new beginning for an old idea, Nuclear Engineering and Design 240, 1644-1656, 2010

[12]. Dalin Zhang et al., Development of a safety analysis code for molten salt reactors, Nuclear Engineering and Design 239, 27782785, 2009

[13]. Guiqiu Zheng et.al., Corrosion of 316 stainless steel in high temperatur molten Li2BeF4 (FLiBe) salt, Journal of Nuclear Materials 461, pp.143-150, 2015 
[14]. S. Delpech, et.al, Reactor physic and reprocessing scheme for innovative molten salt reactor system, Journal of Fluorine Chemistry 130, pp.11-17, 2009

[15]. Jianhui Wu et.al., Flow effect on $135 I$ and $135 X e$ evolution behavior in a molten salt reactor, Nuclear Engineering and Design 314, pp.318-325, 2017

[16]. Mitch Abeln et.al, ThorCon breeder reactor design, molten salt thorium reactor, University of Wisconsin-Madison, http://mattglattfelder.com/Final\%20Draft.pd f

[17]. Jack Devanney,et.al., ThorCon-the doable molten salt reactor executive summary,http://thorconpower.com/docs/exe c_summary2.pdf

[18]. Dane Wilson, ThorCon: Powering up our world status report, https://public.ornl.gov/conferences/MSR201 6/docs/Presentations/MSR2016-day2-06Dane-Wilson-Thor-Con-ORNL.pdf

[19]. Patrick Doyle, ThorCon Power, http://thorconpower.com

[20]. IAEA, Status report - reactor, https://aris.iaea.org/PDF/ARISThorCon9.pdf

[21]. IAEA, ThorCon molten salt reactor, http://thorconpower.com/wpcontent/uploads/2014/12/ARISThorCon10.p $\underline{\mathrm{df}}$

[22]. Jan Uhlır, Chemistry and technology of molten salt reactors - history and perspectives, Journal of Nuclear Materials 360, pp.6-11, 2007

[23]. T. Kamei, S. Hakami, Evaluation of implementation of thorium fuel cycle with $L W R$ and MSR, Progress in Nuclear Energy 53, pp.820-824, 2011

[24]. Howard Chiang et.al., Liquid fluoride thorium reactors: traditional nuclear plant comparison analysis and feasibility study, Energy \& Energy Policy, The University of Chicago December 8, 2014, Team10EnergyFinalPaper.pdf

[25]. D. F. Williams et.al., March 2006, Assessment of Candidate molten salt coolants for the advanced high-temperature reactor (AHTR), ORNL/TM-2006/12, http://large.stanford.edu/courses/2015/ph2 41/kelaita1/docs/124584.pdf

[26]. Yousif Kelaita, Feb. 2015, Molten Salt Reactors http://large.stanford.edu/courses/2015/ph2 41/kelaita1/

[27]. D. T. Ingersoll, Dec. 2005, Status of physics and safety analyses for the liquid-saltcooled very high-temperature reactor (LSVHTR), ORNL/TM-2005/218, http://large.stanford.edu/courses/ 015/ph241/kelaita1/docs/124473.pdf

[28]. Trevor Griffiths et.al., July 2015, MSR review, feasibility of developing a pilot scale molten salt reactor in the UK, , http://www.energyprocessdevelopments.co m/uploads/EPD\%20MSR\%20Review\%20Fea sibility\%20Study\%20July\%202015\%201.02. pdf

[29]. Juan Hou et al., Effects of exposing duration on corrosion performance in weld joint of $\mathrm{Ni}-\mathrm{Mo}-\mathrm{Cr}$ alloy in FLiNaK molten salt, Journal of Fluorine Chemistry 191, pp.110-119, 2016

[30]. Fan-Yi Ouyang, et.al., Effect of moisture on corrosion of Ni-based alloys in molten alkali fluoride FLiNaK salt environments, Journal of Nuclear Materials 437, pp.201207, 2013

[31]. V. Ignatiev et.al., Molten salt actinide recycler and transforming system without and with Th-U support: Fuel cycle flexibility and key material properties, Annals of Nuclear Energy 64, pp.408-420, 2014

[32]. Rod Adams, Sept 2016, Terrestrial Energy's Advanced Nuclear Technology the IMSR - takes several steps forward, Forbes

https://www.forbes.com/sites/rodadams/20 16/09/14/terrestrial-energys-advancednuclear-technology-the-imsr-takesseveral-steps-forward/\#37e0b7df74aa

[33]. Luke C. Olson et.al., Materials corrosion in molten $\mathrm{LiF}-\mathrm{NaF}-\mathrm{KF}$ salt, Journal of Fluorine Chemistry 130, pp.67-73, 2009

[34]. Jie Qiu, et. al., Compatibility of container materials with $\mathrm{Cr}$ in molten FLiNaK salt, Journal of Fluorine Chemistry 168, pp.6974,2014

[35]. Robert $\mathrm{H}$ and Ralph M, Liquid Fluoride Thorium Reactors An old idea in nuclear power gets reexamined, American Scientist, Volume 98, 2010. 